\title{
Generation and characterization of radiolabelled nanosized carbonaceous aerosols for human inhalation studies
}

Jérémie Pourchez ${ }^{a, b, c}$, lolanda M. D. Albuquerque-Silva ${ }^{a, b, c}$, Michèle Cottier $^{a, c, d, e, f}$, Anthony Clotagatide ${ }^{\mathrm{e}}$, Laurent Vecellio ${ }^{\mathrm{g}, \mathrm{h}}$, Marc Durand ${ }^{\mathrm{a}, \mathrm{c}, \mathrm{i}}$, Francis Dubois $^{\mathrm{a}, \mathrm{c}, \mathrm{d}, \mathrm{e}, \mathrm{f}}$

a LINA, EA 4623, F-42023, Saint-Etienne, France

b Ecole Nationale Supérieure des Mines de Saint-Etienne, Centre Ingénierie et Santé, F-42023, Saint-Etienne, France

${ }^{c}$ SFR IFRESIS, F-42023, Saint-Etienne, France

d Université Jean Monnet, Faculté de Médecine, F-42023, Saint-Etienne, France

${ }^{\mathrm{e}} \mathrm{CHU}$ de Saint-Etienne, F-42055, Saint-Priest en Jarez, France

${ }^{f}$ Université de Lyon, F-42023, Saint-Etienne, France

${ }^{9}$ DTF Aerodrug - Diffusion Technique Française, Tours, France

h INSERM U1100-EA6305, Université François Rabelais, Tours, France

${ }^{i}$ Centre Hospitalier Emile Roux, F-43012, Le Puy en Velay, France

Correspondence to: Jérémie POURCHEZ, Ecole Nationale Supérieure des Mines de Saint-Etienne, Centre Ingénierie et Santé, 158 Cours Fauriel 42230, France. Telephone / Fax number: + 33477420180 / +334774996 94, mail: pourchez@emse.fr 
2

3

4

6

7

8

9

\section{ABSTRACT}

New insights on the output of a commercial Technegas generator were proposed in order to optimize the generation of a radioactive nanosized aerosol for human inhalation studies. Parameters influencing Technegas generated aerosols (i.e. gaseous atmosphere, generation temperature and storage duration) were analyzed by a combination of size-fractionation and gamma-scintigraphy detection to determine the aerosol aerodynamic-related distributions. It was found that the total radioactivity per mass and number concentrations of aerosols was mostly influenced by the burn temperature, while the radiolabelling of particles was mostly driven by their surface area. ${ }^{99 \mathrm{~m}} \mathrm{Tc}$ labeled nanosized carbonaceous primary particles appear mainly to result from nucleation/condensation of the supersaturated vapor during the burning step, and then coalesce into larger particles due to coagulation processes during the residence time in the expansion chamber. We showed that the burn temperature and the aerosol residence time were the main parameters influencing the particle size distribution. Under optimized operating conditions, the amount of radiolabelled nanoparticles substantially increased since the radioactivity median aerodynamic diameter was reduced by half ( $250 \mathrm{~nm}$ - GSD of 2.5) compared with the standard operating conditions of the Technegas generator (450 nm - GSD of 3.4).

KEYWORDS: Technegas; ELPI; radiolabelled nanosized aerosols 


\section{MAIN TEXT}

\section{Introduction}

Radiolabelled aerosols are widely used to study airborne particle deposition patterns in the lung as well as lung clearance (Möller et al., 2006; Sanchez-Crespo et al., 2011; Carvalho et al., 2011). Among all the radiolabelled aerosols clinically used in patients, one of the most convenient is the "Technegas technique" widely used to perform lung ventilation scintigraphy as a diagnostic technique in nuclear medicine. The aerosol produced is commonly known as Technegas, an ultrafine suspension of carbon particles labeled with technetium $\left({ }^{99 \mathrm{~m}} \mathrm{Tc}\right)$. Technegas preparation takes place in a specially designed machine, called the Technegas generator, where a solution of sodium pertechnetate is loaded into a graphite crucible and evaporated until dry. Technegas is then generated by heating to $2550{ }^{\circ} \mathrm{C}$ in an atmosphere of pure argon. The number size distribution of Technegas particles is mainly below $100 \mathrm{~nm}$ (Vita Medical Ltd., 2000). Since more than 2 decades, this radioactive aerosol is regularly used as a ventilation scintigraphy agent, and the device is approved for human application without any toxicological issues (Jögi et al., 2010, Senden et al., 1997; Lloyd et al., 1995; Burch et al., 1986). Due to the short half-life of ${ }^{99 \mathrm{~m}} \mathrm{Tc}(6.02 \mathrm{~h})$, the radiation dose can be kept low $(<0.1 \mathrm{mSv})$ even though the resulting high activities allow high quality gamma-camera imaging in nuclear medicine.

Under standard operating conditions, the Technegas generator produces airborne particles with leaching rates $>10 \%$ which are too high for clearance studies. Since $\mathrm{NaCl}$ contained in the ${ }^{99 \mathrm{~m}} \mathrm{Tc}$-eluate also evaporates and condenses during the burning step, the particles have hygroscopic properties and the radiolabel leaches from them. Recently Moeller et al. (2006) proposed several modifications to the operating conditions of the Technegas generator to avoid these drawbacks such as 
the use of $\mathrm{NaCl}$ free ${ }^{99 \mathrm{~m}} \mathrm{Tc}$-eluate. In addition the particles could be labeled by ${ }^{111} \mathrm{In}$ (Sanchez-Crespo et al., 2011) or ${ }^{68} \mathrm{GaCl}_{3}$ (Borges et al., 2011) instead of ${ }^{99 \mathrm{~m}} \mathrm{Tc}$ to extend the investigation time of clearance studies from 1 day to a few weeks.

Although it is generally accepted that the Technegas generator produces a smaller particle size than other conventional radiolabelled aerosols, few data are available about its particle size characteristics. To the best of our knowledge no data have yet been reported on the relationship between radioactivity aerodynamic diameter (AMAD) although this parameter is crucial to assess deposition patterns. Even the median diameter remains poorly defined in the range from about 200 to 400 nm (Borges et al. 2011, Lemb et al., 1993; Strong and Agnew, 1989; Möller et al., 2006). In fact, clinical experiments in nuclear medicine indicate that radiolabelled Technegas particles are likely to impact on obstructions within the respiratory tract, which is a behavior typically attributed to micrometer sized aerosols (Jögi et al., 2010).

The radiolabelling mechanism and radiolabelling efficiency of airborne particles related to their aerodynamic size also remain poorly understood. Therefore, this study aims at new insights on the output of a Technegas device generating ${ }^{99 \mathrm{~m}} \mathrm{Tc}$ labeled nanosized carbonaceous aerosols. The physical properties of the airborne nanoparticles in term of radiolabelling efficiency, number, mass and surface area concentrations are characterized by using a combination of size-fractionation and gamma-scintigraphy detection. Based on the experimental methodology previously developed by Moeller et al. (2006), we also propose a better understanding of the effect of Technegas generator operating conditions on the characteristics of the radiolabelled particle size distributions. Finally, we also describe optimal operating conditions to generate radiolabelled carbonaceous nanoparticles. 


\section{Material and methods}

The generation of Technegas was first reported in 1986, as a simple process consisting of evaporating Technetium $\left({ }^{99 \mathrm{~m}} \mathrm{Tc}\right)$ containing eluate in a graphite crucible at $2500^{\circ} \mathrm{C}$ (Burch et al., 1986). The Technegas generator is essentially a miniature high temperature furnace (Figure 1). It uses a combination of graphite in an argon atmosphere to chemically reduce the pertechnetate ion $\mathrm{TcO}_{4}{ }^{-}$contained in the ${ }^{99 \mathrm{~m}} \mathrm{Tc}$ sodium pertechnetate solution to metallic technetium (Tc), and then produce metallic aerosol particles by vaporizing both carbon and technetium elements. The inert atmosphere is critical to produce pure carbon or metallic aerosols (Evans et al., 2003). The crucible is the source of graphite vapour which ultimately coats the technetium metal. An AC electrical current passes through two conducting substrates (electrodes and crucible) possessing relatively low vapour pressure. The metallic aerosol forms first by nucleation/condensation of the vapour, followed by agglomeration of airborne nanoparticles composed of hexagonal platelets of metallic technetium ${ }^{99 \mathrm{~m}} \mathrm{Tc}$ ) closely encapsulated with a thin layer of graphitic carbon. During Technegas production, particles are not equally radiolabelled. The rapid volatilization of the species involved and the surface passivation of the resulting metallic aerosol are major factors influencing particles formation and stabilization, which may proceed differently according to particle size distribution (Senden et al., 1997).

In this work, the Technegas generator (Cyclomedica Pty Ltd, Australia) was operated in its "maintenance mode", which allows modifying its operating conditions. A pyrometer was coupled to the generator in order to control burn temperature. For aerosol production, a standard graphite crucible was previously humidified with $99 \%$ ethanol in order to increase its wetability and then filled with a $200 \mathrm{MBq}{ }^{99 \mathrm{~m}} \mathrm{Tc}$-sodium pertechnetate solution placed in the Technegas generator chamber. The produced 
aerosol was subsequently analyzed by an electrical low pressure impactor (ELPI, Dekati Ltd., Finland) and a gamma camera (Millenium, GE, USA), to determine the particle size distribution both by weight, number, surface area and radioactivity. The $\mathrm{NaCl}$ content in ${ }^{99 \mathrm{~m}} \mathrm{Tc}$-eluate was also evaluated with respect to its influence on the final particle size distribution. All experiments were performed in triplicate and statistically analyzed (unpaired t-test).

\subsection{Aerosol generation parameters}

Under standard clinical operating conditions, the aerosol production is initiated through the "simmer" stage, which is characterized by a modification of the generator chamber atmosphere by argon flushing and a slight heating of the crucible up to $80^{\circ} \mathrm{C}$ for a 6 minute duration (Vita Medical Ltd., 2000). Under these conditions, the ${ }^{99 m} \mathrm{Tc}$ eluate is evaporated to dryness, providing an intimate contact between the crucible and the species of ${ }^{99 m} \mathrm{Tc}$-sodium pertechnetate solution (Senden et al., 1997). Subsequently, the "burn" stage begins in which the crucible is finally heated to $2550^{\circ} \mathrm{C}$ for 10 seconds (Vita Medical Ltd., 2000). This heating leads to technetium and carbon evaporation with subsequent condensation and aerosol formation. It is therefore reasonable to conclude that the major parameters influencing aerosol generation are the burn temperature, the duration of the simmer and the burn stages. Another important parameter is the residence time in the expansion chamber. During clinical procedures, a delay (i.e. a residence time in the expansion chamber) occurs between Technegas generation and its delivery to the patient. This delay is usually on the order of 2 minutes. During the residence time in the expansion chamber, particles are able to coagulate and agglomerate, with a significant impact on the 
122 subsequent size distribution of the radioactive aerosol delivery to the patient (Möller 123 et al., 2006).

124 The standard clinical parameters for Technegas production are prescribed as 6 minutes of simmering, followed by $10 \mathrm{~s}$ of burning at $2500^{\circ} \mathrm{C}$ followed by 2 minutes of residence time. However, in order to reduce the consumption of the generator electrodes, in this work the standard burn stage duration was reduced to 5 seconds instead of 10. The proposed change of operating conditions of the Technegas generator was based on a previous study from Möller et al. (2006). The analyses of particle size distribution were performed by varying each generation parameter: (I) simmer duration (6 - $15 \mathrm{~min})$; (II) burn temperature $\left(1900-2800^{\circ} \mathrm{C}\right)$; (III) burn duration $(2-15 \mathrm{~s})$ and (IV) aerosol residence time $(0.5-10 \mathrm{~min})$. The operating conditions of the Technegas generator were summarized in Figure 2.

\subsection{Particle size distributions}

Aerosol size distributions were determined using the ELPI low pressure impactor. The ELPI classifies by aerodynamic diameter, in 12 size fractions ranging from 10 $\mu \mathrm{m}$ to $7 \mathrm{~nm}$ (Virtanen et al., 2001; Marjamäki et al., 2000). The number concentration was converted to mass and surface area concentrations assuming the graphite crucible density $\left(2.13 \mathrm{~g}_{\mathrm{cm}} \mathrm{cm}^{-3}\right)$ for the particles. Differential distributions and normalized cumulative distributions are shown in accordance with the European standard EN 13544-1 for respiratory therapy equipment, which is widely employed for pharmaceutical aerosols. The cumulative distributions were normalized, i.e. data were expressed in $\%$ where $100 \%$ corresponds to total radioactivity (from gammacamera measurements) or total mass/number/surface area (from ELPI calculations) deposited on all the 12 collection plates of the cascade impactor. 


\subsection{Radioactivity measurements}

A combination of ELPI size fractionation and gamma scintigraphy detection was used to determine the aerodynamic radioactivity size distribution. For this purpose, the aerosol was collected on cellulose substrates inserted on the collection plates of the impactor. The radioactivity of airborne particles deposited on each collection substrate was determined by gamma scintigraphy imaging during a 2 minutes acquisition time. The distribution of radioactivity is presented versus the ELPI stage mid-point aerodynamic diameter.

\subsection{Electron microscopy observations and chemical analysis}

Field Emission Gun Scanning Electron Microscopy (FEG SEM, Jeol JSM 6500F) was used to analyze the Technegas particles deposited within the ELPI stages. SEM observations coupled with image analysis also provided a mean geometric particle diameter for each size class of the ELPI.

The sodium and chloride concentrations in the Tc-eluate were obtained by ion chromatography with a Dionex apparatus composed of a GP50 pump, a CS12A column for cation analysis, a AS11HC column for anions, a CD conductometric detector and a UV-visible detector. The presence of $\mathrm{NaCl}$ in the airborne particles was characterized using energy-dispersive X-ray spectroscopy (EDX) coupled with a scanning electron microscope. The EDX analytical technique was used for the elemental analysis of airborne particles (except carbon and technetium elemental detection). The sodium, chloride and technetium content of airborne particles were measured using X-ray photoelectron spectroscopy (XPS). XPS is a quantitative spectroscopic technique for the elemental composition. 


\section{Results}

\subsection{Technegas aerosol under standard operating conditions}

A linear correlation was found between the geometric diameter of particles calculated by image analysis from SEM images and the corresponding mid-point aerodynamic diameter of the ELPI stage (Figure 3). Results show a particle distribution composed of a predominantly carbonaceous nature for the ultrafines particles (in the $30-300 \mathrm{~nm}$ size range) and the dominant $\mathrm{NaCl}$ content of the micron sized particles (Figure 3). The sodium chloride content of numerous micrometer sized particles was clearly put in evidence by EDX spectroscopy during SEM observations and XPS analysis. On the ELPI stages corresponding to mid-point aerodynamic diameters higher than $1 \mu \mathrm{m}$, SEM images also show the presence of coagulated carbonaceous particles (data not shown but similar to Figure 7), which precluded the correct determination of their geometric diameter, leading to slight deviations from ELPI measurements even if the overall correlation remains quite good.

The particle size distributions of the aerosol obtained under standard operating conditions used in clinical routine are first presented in terms of number, surface area, mass and radioactivity (Figure 4). Number distributions are dominated by nanoparticles with aerodynamic diameters lower than $100 \mathrm{~nm}$ with a Count Median Aerodynamic Diameter (CMAD) of $40 \mathrm{~nm}$ (GSD of 2.9). However, radioactivity distributions indicate that radiolabelled particles are mostly distributed in the range between $100 \mathrm{~nm}$ and $1 \mu \mathrm{m}$, providing an Activity Median Aerodynamic Diameter (AMAD) of $450 \mathrm{~nm}$ (GSD of 3.4). Radioactivity distributions were found to be in good accordance with surface area distributions, characterized by a Surface Median Aerodynamic Diameter (SMAD) of $540 \mathrm{~nm}$ (GSD of 2.1). Finally, mass distributions 
showed particles exclusively distributed in the size range above $100 \mathrm{~nm}$, leading to a Mass Median Aerodynamic Diameter (MMAD) of $820 \mathrm{~nm}$ (GSD of 2.7) .

The combination of aerodynamic and radioactivity measurements provides new insights into the radiolabelling process. A radiolabelling efficiency was defined as the ratio between activity (in fact radioactivity, in $\mathrm{Bq}$ ) and mass from particles deposited on each ELPI stage. According to Figure 5, particle radiolabelling is most efficient in the nanometer range and than decreases continuously with aerodynamic diameter.

The electric charge level of the freshly generated airborne Technegas particles was also checked by ELPI (using the ELPI with the corona charger OFF) in order to verify that the original electric charge of the particles does not affect the ELPI detection based on current measurement. Results show that the aerosol particles are weakly charged and that the charge distribution depends to the aerodynamic particle size. Particles are positively charged (13 fC) for sizes from 28 to $262 \mathrm{~nm}$, negatively charged $(-12 \mathrm{fC})$ in the range $262 \mathrm{~nm}$ to $1.6 \mu \mathrm{m}$, and finally neutral for sizes greater than $1.6 \mu \mathrm{m}$. In this case, the corona charger produces a sufficient amount of positive ions to first neutralize and then charge the particles normally up to $7500 \mathrm{fC}, 500$ times higher than the original electric charge of the particles. Furthermore, the use of cellulose substrates for particles recovery on the ELPI stages has no significant influence $(p<0.05)$ on the Technegas particle size distribution. Both methods generate aerosol with an AMAD of 445 (GSD of 3.0) and $450 \mathrm{~nm}$ (GSD of 2.7) respectively (Table 1).

\subsection{Technegas aerosol characteristics under modified operating conditions}

We now show that the modified operating conditions significantly influence the particle size distribution (Figure 6). Results are also summarized as mean of AMAD 
and GSD in Table 2. An increased simmer increases the amount of nanoparticles

222 significantly. 15 minutes of simmering (instead of $6 \mathrm{~min}$ under standard clinical operating conditions) increase the nanoparticle population by $10 \%$, leading to a reduction of the Technegas AMAD from 450 to $305 \mathrm{~nm}$. Increasing the burn duration from 2 to 10 seconds also reduces the AMAD from 500 to $370 \mathrm{~nm}$. However, increasing the burn duration beyond 10 seconds does not have a significant influence on the aerosol AMAD.

The burn temperature of the crucible, and the aerosol residence time in the expansion chamber, appear to be the main parameters affecting aerosol generation. Therefore, either an increase of burn temperature or a decrease of residence time leads to a substantial reduction of aerosol AMAD and an increased amount of radiolabelled nanoparticles. Increasing the burn temperature from $1900^{\circ} \mathrm{C}$ to $2800^{\circ} \mathrm{C}$ leads to a decrease of AMAD from 510 to $270 \mathrm{~nm}$. A decrease of residence time from 10 minutes to 0.5 minutes gave a decrease of AMAD from 540 to $285 \mathrm{~nm}$. SEM observations showed that the morphology of aerosols particles was also highly dependent on their residence time. Therefore, particle coagulation and agglomeration were visibly reduced for small aerosol residence times (30 seconds) but manifestly present for long residence times (10 minutes) (Figure 7).

Moreover, the total amount of aerosol radioactivity, i.e. the number of technetium atoms fixed on carbonaceous particles, was also strongly influenced by the generation parameters, especially by the burn temperature (Figure 8). Thus, a reduction of temperature to $1900^{\circ} \mathrm{C}$ causes a significant reduction in total radioactivity, up to 4 times lower than in standard clinical operating conditions.

Finally, the radiolabelled particle size was mostly affected by the burn temperature. Thus, an optimization of the generation method is proposed based on 
adjustments of the burn temperature, in order to maximize the production of

247 radiolabelled nanoparticles. This optimized method of radiolabelled aerosol 248 production was performed by two consecutives burn stages, using both extremes of 249 burn temperature of the generator: 5 second burn at $1900^{\circ} \mathrm{C}$ followed by 5 second 250 burn at $2800^{\circ} \mathrm{C}$. The optimized radiolabelled aerosol showed an aerodynamic particle 251 size distribution with an AMAD of $250 \mathrm{~nm}$ (GSD of 2.5), about 2 times smaller than 252 standard Technegas, but to a 15\% increase of the radiolabelled nanoparticles (Figure 253 9).

254 Once the optimized conditions for Technegas production were determined, the 255 influence of the $\mathrm{NaCl}$ content on Tc-eluate was analyzed. Ionic chromatography 256 confirms the very low $\mathrm{NaCl}$ concentration (in the range $20-100 \mathrm{mg} / \mathrm{L}$ ) of the $\mathrm{NaCl}$ free 257 Tc-eluate, by comparison with the $\mathrm{NaCl}$ concentration of $9 \mathrm{~g} / \mathrm{L}$ for $\mathrm{NaCl} \mathrm{Tc}$ eluate. 258 Results further prove that an initially $\mathrm{NaCl}$-free eluate did not significantly modify the 259 particle size distribution (AMAD of $200 \mathrm{~nm}$ ) (Figure 9). 


\section{Discussion}

In the present study, based on a methodology combining radioactivity measurements and aerodynamic size fractionation, for the first time the Technegas size distributions are expressed in terms of size-related radioactivity, characterized by AMAD. Using ELPI based calculations, the aerosol was also characterized by its CMAD, SMAD and MMAD. These calculations are based on positive ion active surface areas measured by ELPI, and the masses of spheres with diameter equal to the midpoint aerodynamic values $\left(D_{a}\right)$ of each stage. Active surface area is generally defined as the surface of a particle that is involved in interactions with the surrounding gas (Fuchs, 1963). Thus, the ELPI provides a real time size-selective (aerodynamic diameter) active surface-area concentration. In this sense the surface area measured by the ELPI is an active surface area quite relevant to describe Tccarbone interactions. The active surface area distribution appears to be the most appropriate form to describe the radiolabelled particles distributions since a good correlation is observed between surface area and radioactivity cumulative distributions (Figure 4). This original data demonstrates that particle radiolabelling is mostly proportional to their active surface area, rather than particle number or mass. In other words, the quantity of technetium atoms fixed on the carbonaceous particles is mainly dependent to their active surface area.

Further, the Technegas MMAD (820, GSD of 2.7) was found to be almost 20 times higher than its CMAD, which trivially indicates that Technegas nanoparticles, although abundant in number, are not significant in mass. However, activity measurements provide an AMAD (450 nm, GSD of 3.4) corresponding to the half of Technegas MMAD, which can be explained by the fact that its nanoparticles, although insignificant in mass, have a considerable radioactivity. The radiolabelling 
efficiency of Technegas particles, expressed by means of activity-to-mass ratio, also indicates that particle radiolabelling was more efficient on the nanometric scale (Figure 5). This result highlights the role played by particle surface area during radiolabelling. In this sense, the higher active surface area to volume ratio of nanoparticles (compared to micrometric particles) can easily explain the continuous decrease of radioactivity to mass ratio with the increase of aerodynamic diameter. The remarkable radiolabelling efficiency of nanoparticles can also be explained by their mode of production. In previous work, Senden et al. (1997) observed that the radioactivity only leaves the crucible at the melting point for technetium $(2250 \pm$ $50^{\circ} \mathrm{C}$ ), which probably indicates that there is a passive mechanism of particle ejection from the crucible (i.e. the evaporation of the metal). Once in the vapor phase, technetium may condense as a metallic aerosol, being instantly passivated by condensed carbon (Senden et al., 1997).

Our data support the assumption that the generation of Technegas nanoparticles is driven by a mechanism quite similar to aerosol produced by spark discharge generators. Technegas nanoparticle generation could be therefore explained by a simultaneous ablation of technetium and graphite, caused by the striking of an alternative current arc from the thermionic plasma inside the crucible (Vita Medical Ltd., 2000). ${ }^{99 \mathrm{~m}} \mathrm{Tc}$ labeled nanosized carbonaceous particles appear mainly to result from nucleation/condensation during the burning step followed by coagulation processes during the residence time in the expansion chamber. Nevertleless, these mechanisms are still not entirely proven and require further investigations.

All the operating conditions of the Technegas generator (i.e. simmer, burn duration, burn temperature and aerosol residence time) show an influence on the particle size distribution (Figure 6). A decrease of aerosols AMAD was observed with increasing 
311 simmer and burn durations. These parameters apparently facilitate ablation and

312 condensation phenomena and thus contribute to the AMAD reduction. Although the 313 simmer and burn duration had some impact on the particle size distribution, stronger 314 modifications were observed by adjusting on the residence duration in the expansion 315 chamber and the burn temperature. Longer residence times obviously lead to 316 coagulation and a higher AMAD (Table 2, Figure 7). This result confirms the relative 317 instability of freshly radiolabelled nanoparticles over the timeshown in previous 318 studies (Llyod et al.,1995, Möller et al., 2006). A noticeable reduction of AMAD from $319510 \mathrm{~nm}$ (GSD of 3.0) to $270 \mathrm{~nm}$ (GSD of 2.7) was observed for an increase of burn 320 temperature from $1900^{\circ} \mathrm{C}$ to $2800^{\circ} \mathrm{C}$. Furthermore, burn temperature was the 321 parameter which had the strongest influence on the total aerosol radioactivity (Figure 322 8). As the burn temperature plays a major role on the output of Technegas device, an optimized method has been proposed which is based on a temperature of $1900^{\circ} \mathrm{C}$ followed by $2800^{\circ} \mathrm{C}$ to reduce the AMAD (Figure 9).

Finally, we demonstrate that the absence of sodium chloride in the initial pertechnetate eluate does not significantly modify the particle size distribution (AMAD of $200 \mathrm{~nm}$ ) compared to usual $\mathrm{NaCl}$ pertechnetate eluate (Figure 9). This result suggests that $\mathrm{NaCl}$ crystals generated using $\mathrm{NaCl}$ Tc-eluate are poorly radiolabelled compared to carbonaceous nanoparticles. Previous studies (Moller et al., 2006, Wiebert et al., 2006a, 2006b) demonstrated that the removal of $\mathrm{NaCl}$ from ${ }^{99 \mathrm{~m}} \mathrm{Tc}$ sodium pertechnetate also yielded low leaching rates of radiolabel from particles of 332 below $4 \%$ within $24 \mathrm{~h}$, and also guaranteed non-hygroscopic aerosol properties. The removal of $\mathrm{NaCl}$ from the Tc-eluate therefore seems to have several advantages. 


\section{Conclusion}

The particle size distribution of the Technegas generator has been characterized from combined measurements of radioactivity (using a gamma camera) and aerodynamic sizing (using ELPI). Under standard clinical operating conditions, Technegas shows a radioactivity median aerodynamic diameter (AMAD) of $450 \mathrm{~nm}$ (GSD of 3.4). The particle size distribution and the total radioactivity of the aerosol are mostly influenced by the burn temperature. We proposed an optimized procedure to produce radiolabelled nanoparticles using the commercial Technegas generator consisting of two consecutive burns at $1900^{\circ} \mathrm{C}$ and $2800^{\circ} \mathrm{C}$. Under optimized conditions, the median diameter of Technegas can thereby be reduced by half $(250$ $\mathrm{nm})$, together with a substantial increase of its radiolabelled nanoparticle population.

Aerosols containing a greater amount of radiolabelled nanoparticles may permit better particle deposition within the respiratory tract. In this context an improvement of lung ventilation scintigraphy in nuclear medicine is conceivable. These new insights appear also valuable to assess deposition patterns of well-defined nanoparticles within the respiratory tract, in the case of inhalation toxicology and drug delivery by aerosol therapies. Finally, the proposed approach to optimize the generation of radioactive nanosized aerosol using the technegas generator can be coupled with other previous modifications such as a higher stable radiolabelling over time by removing $\mathrm{NaCl}$ from the Tc-eluate, or the possibility of ${ }^{111} \mathrm{In} /{ }^{68} \mathrm{GaCl}_{3}$ labbelling, to enhance alveolar pattern deposition and provide potential clinical improvements on inhalation studies. 


\section{ACKNOWLEDGEMENTS}

The authors would like to acknowledge the financial support of the Regional

360 French Association for Aid to Chronic Respiratory Failure Patients (ARAIR), Saint-

361 Etienne Métropole and the Conseil Général de la Loire, as well as the helpful

362 conversations and experimental support of the Cyclopharma Laboratoires (France).

363 The authors would like also to thank the editor for all corrections and helpful

364 comments which greatly contribute to this paper. Finally, special thanks to Laurent

365 Navarro (Ecole Nationale Supérieure des Mines de Saint-Etienne, Centre Ingénierie

366 et Santé, France) for his contribution to the image analysis and algorithm

367 development on SEM images. 
370 Borges, J.B., Velikyan, I., Langström, B., Sörensen, J., Ulin, J., Maripuu, E.,

371 Sandström, M., Widström, C., Hedenstierna, G. (2011). Ventilation distribution

372 studies comparing Technegas and "Gallgas" using ${ }^{68} \mathrm{GaCl}_{3}$ as the label. Journal of 373 Nuclear Medicine, 52, 206-209.

375 Burch, W.M., Sullivan, P.J., McLaren, C. (1986). Technegas - a new ventilation 376 agent for lung scanning. Nuclear Medicine Communications, 7, 865-871.

378 Carvalho, T.C., Peters, J.I., and Williams, R.O. (2011) Influence of particle size on 379 regional lung deposition - What evidence is there? International Journal of 380 Pharmaceutics, 406, 1-10.

Dekati Ltd. ELPI in pharmaceutical measurements. In: Dekati Ltd Application Note. 2007.

Evans, D.E., Harrison, R.M., Ayres J.G. (2003). The generation and characterization of elemental carbon aerosols for human challenge studies. Journal of Aerosol Science, 34, 1023-1041.

Fuchs, N. (1963) On the stationary charge distribution on aerosol particles in a 390 bipolar ionic atmosphere. Geofisica Pura e Applicata, 56, 185-193. 
392 Jögi, J., Jonson, B., Ekberg, M., Bajac, M. (2010). Ventilation-Perfusion SPECT with 393 99mTc-DTPA versus Technegas: A head-to-head study in obstructive and 394 nonobstructive disease. Journal of Nuclear Medicine, 51, 735-741

395

Lemb, M., Oei, T.H., Eifert, H., Günther, B. (1993). Technegas: a study of particle 397 structure, size and distribution. European Journal of Nuclear Medicine, 20, 576-579.

Lloyd, J.J., Shields, R.A., Taylor, C.J., Lawson, R.S., James, J.M., Testra, H.J. 400 (1995). Technegas and Pertechnegas particle size distribution. European Journal of Nuclear Medicine, 22, 437-476

402

Marjamäki, M., Keskinen, J., Chen, D.R., Pui, D.Y.H. (2000). Performance evaluation 404 of the electrical low-pressure impactor (ELPI). Journal of Aerosol Science, 31, 249405 261.

406

Möller, W., Felten, K., Seitz, J., Sommerer, K., Takenaka, S., Wiebert, P., Philipson, K., Svartengren, M., Kreyling, W.G. (2006). A generator for the production of radiolabelled ultrafine carbonaceous particles for deposition and clearance studies in the respiratory tract. Journal of Aerosol Science, 37, 631-644.

Sanchez-Crespo, A., Klepczynska-Nyström, A., Lundin, A., Larsson, B.M.

413 Svartengren, M. (2011). Indium-labeledultrafine carbon particles; a novel aerosol for pulmonary deposition and retention studies. Inhalation Toxicology, 23,121-128. 
416 Senden, T.J., Moock, K.H., Gerald, J.F., Burch, W.M., Browitt, R.J., Ling, C.D., and 417 Heath, G.A. (1997). The physical chemical nature of Technegas. Journal of Nuclear 418 Medicine, 38, 1327-1333.

419

420 Strong, J.C., Agnew, J.E. (1989). The particle size distribution of Technegas and its 421 influence on regional lung deposition. Nuclear Medicine Communications, 10, 425422430.

423

Virtanen, A., Marjamäki, M., Ristimäki, J., Keskinen, J. (2001). Fine particle losses in 425 electrical low-pressure impactor. Journal of Aerosol Science, 32, 389-401.

Vita Medical Ltd. Technegas Service Manual Document N70305. 2000:P2-4.

428

429

Wiebert P., Sanchez-Crespo A., Falk R., Philipson K., Lundin A., Larsson S., et al. 430 (2006a). No significant translocation of inhaled 35-nm carbon particles to the circulation in humans Inhalation Toxicology 18, 741-747.

432

433 Wiebert, P., Sanchez-Crespo, A., Seitz, J., Falk, R., Philipson, K., Kreyling, W. G., 434 Moller, W., Sommerer, K., Larsson, S., and Svartengren, M. (2006b). Negligible 435 clearance of ultrafine particles retained in healthy and affected human lungs. 436 European Respiratory Journal, 28, 286-290. 
441 TABLE 1. Influence of generator mode and ELPI collection substrates on aerosols 442 particle size distributions: radioactivity median aerodynamic diameters (AMAD) and 443 geometric standard deviation (GSD).

444 TABLE 2. Radioactivity median aerodynamic diameters (AMAD) and geometric 445 standard deviation (GSD) under standard clinical operating conditions, or under 446 modified and optimized operating conditions (modified generation parameters in 447 bold). 
FIGURE 1. Schematic diagram of the Technegas generator.

452

453

454

455

456

457

FIGURE 2. Operating conditions of the Technegas generator: description of analyzed parameters.

FIGURE 3. EDX analysis coupled with SEM observation of ELPI stage showing carbonaceous nanoparticles (A) and $\mathrm{NaCl}$ crystals (B). Linear correlation between geometric diameter obtained by image analysis on SEM images and corresponding mid-point aerodynamic diameter determined by ELPI.

FIGURE 4. Aerodynamic size distributions of aerosol generated under standard clinical operating mode: differential distributions from ELPI calculations (top) and cumulative distributions from combined ELPI and gamma-camera measurements (bottom).FIGURE 5. Radiolabelling efficiency expressed as radioactivity per mass of particle.

FIGURE 5. Radiolabelling efficiency expressed as activity per particle mass.

FIGURE 6. Operating parameters influencing Technegas aerodynamic particle size distribution. Clinical operating conditions are used as a reference (distribution in black bold line).

FIGURE 7. SEM images of particles deposited on ELPI stage corresponding to midpoint aerodynamic diameter of $2.39 \mu \mathrm{m}$ for residence times of $(A) 30$ seconds and $(B)$ 10 minutes. Arrows indicate agglomerated particles.

FIGURE 8. Total radioactivity of evaluated radio-aerosols: influence of operating parameters $\left({ }^{*}\right.$ : Values are not significantly different, $\left.p<0.05\right)$. 
472 FIGURE 9. Technegas aerodynamic particle size distribution: comparison between

473 standard clinical production, optimized production and optimized production using $474 \mathrm{NaCl}$ free-eluate. 
1 FIGURE 1. Schematic diagram of the Technegas generator.

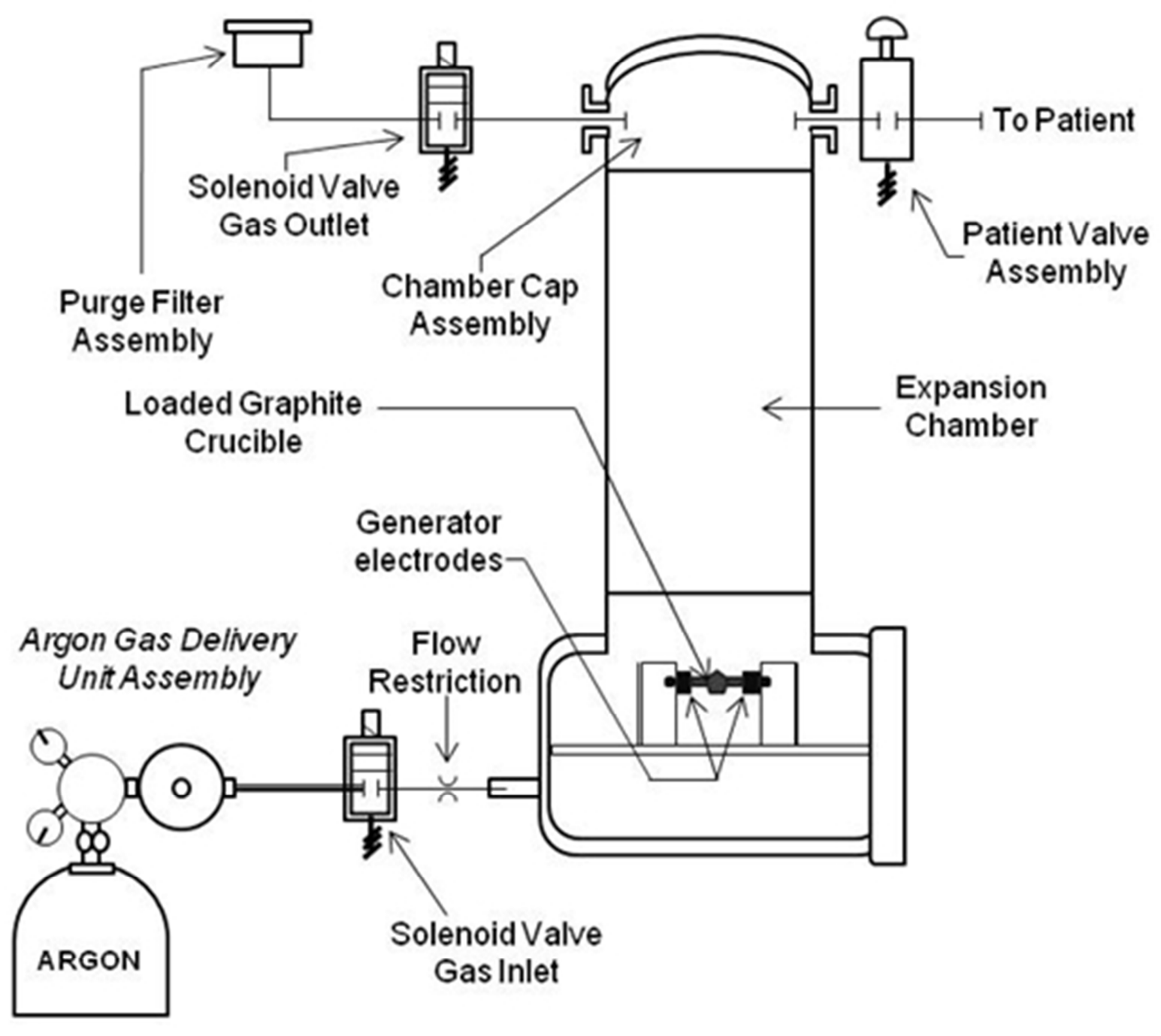


4 FIGURE 2. Operating conditions of the Technegas generator in the maintenance

5 mode : description of analyzed parameters.

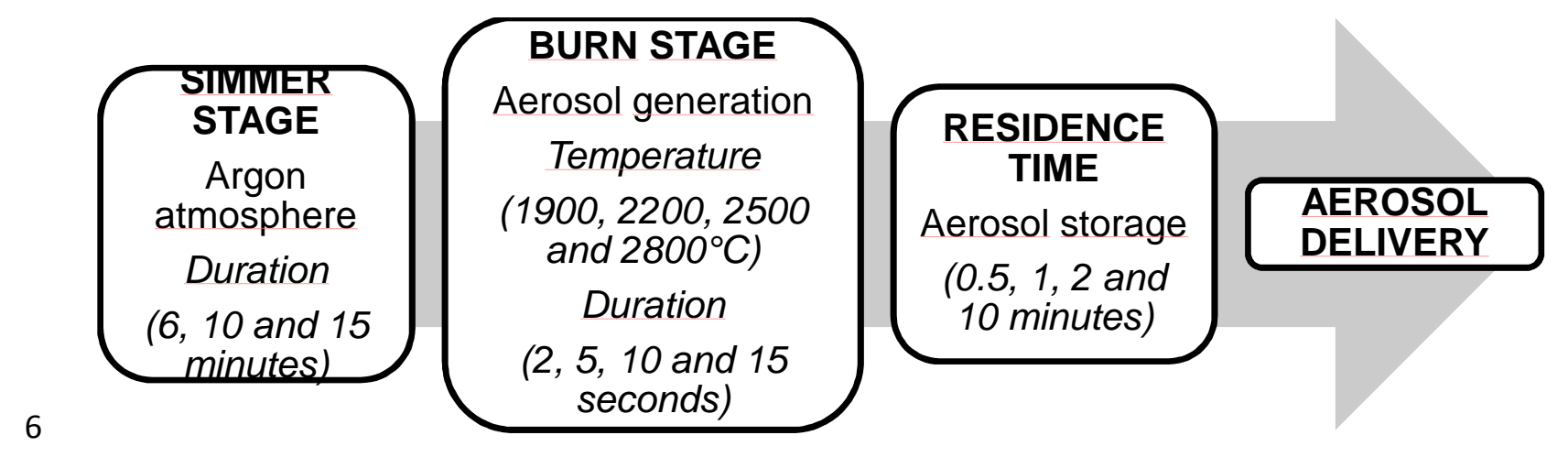


8 FIGURE 3. EDX analysis coupled with SEM observation of ELPI stage showing

9 carbonaceous nanoparticles (A) and $\mathrm{NaCl}$ crystals (B). Linear correlation between 10 geometric diameter obtained by image analysis on SEM images and corresponding 11 mid-point aerodynamic diameter determined by ELPI.
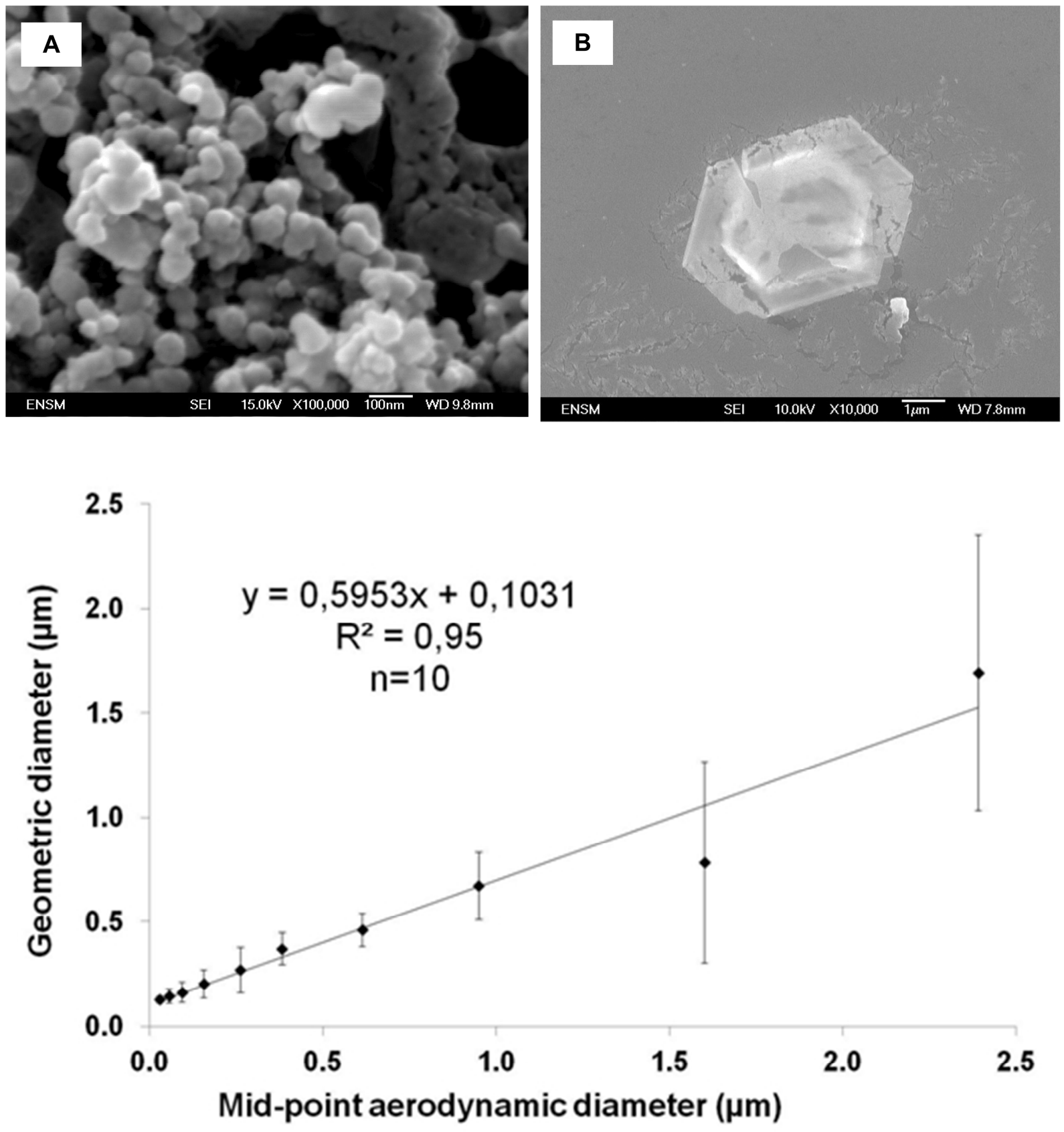
FIGURE 4. Aerodynamic size distributions of aerosol generated under standard clinical operating mode: differential distributions from ELPI calculations (top) and cumulative distributions from combined ELPI and gamma-camera measurements (bottom).

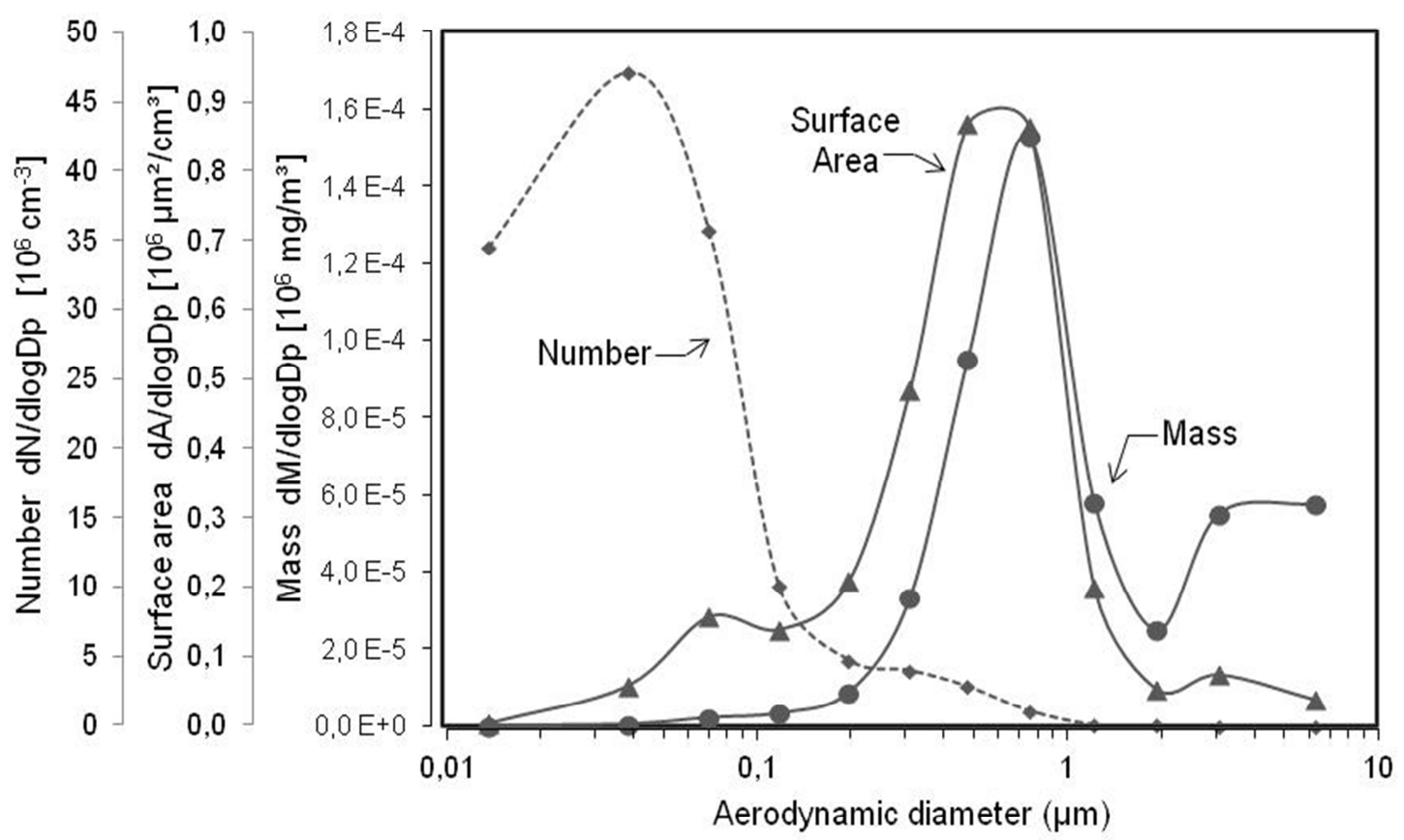

19

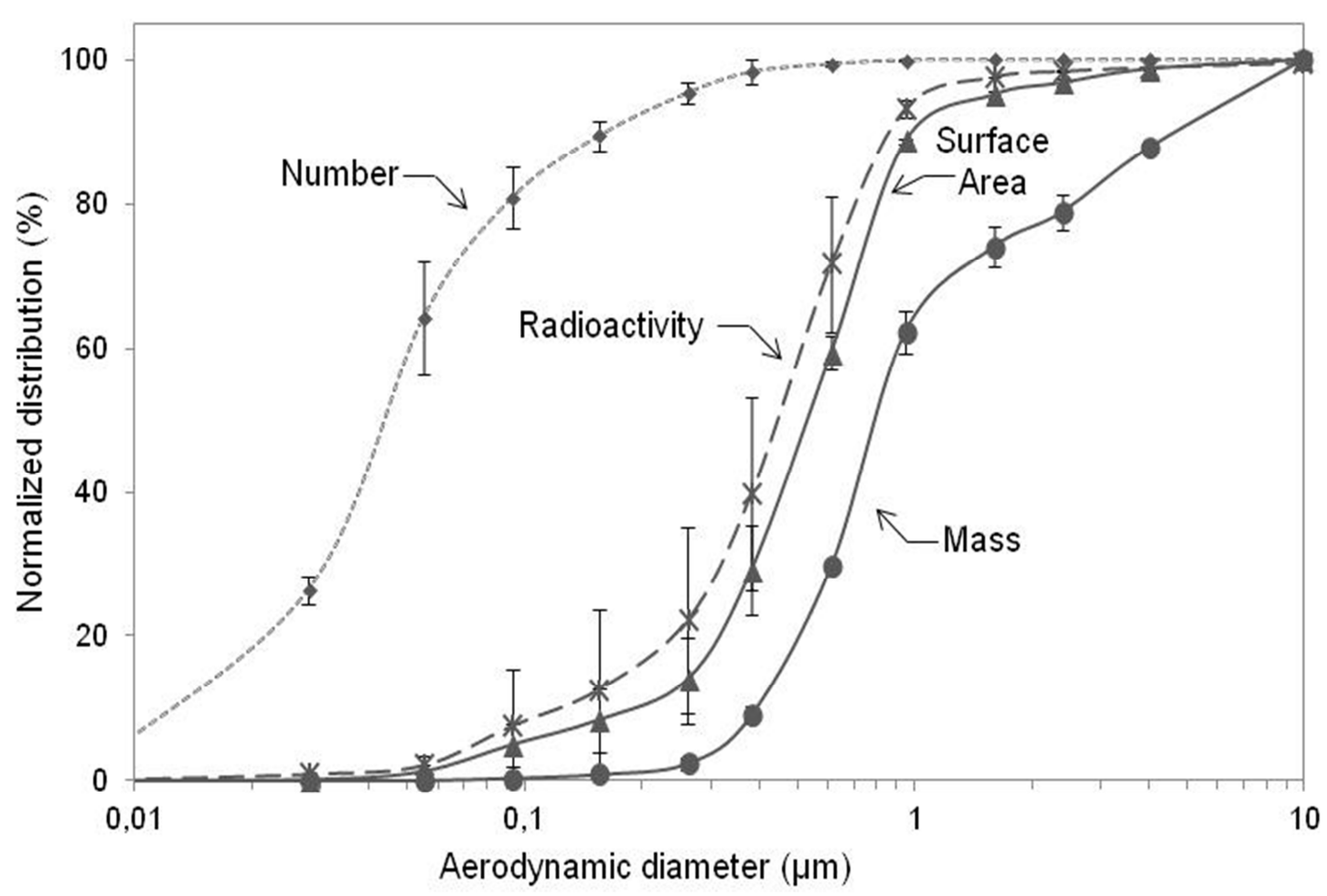


21 FIGURE 5. Radiolabelling efficiency expressed as activity per particle mass.

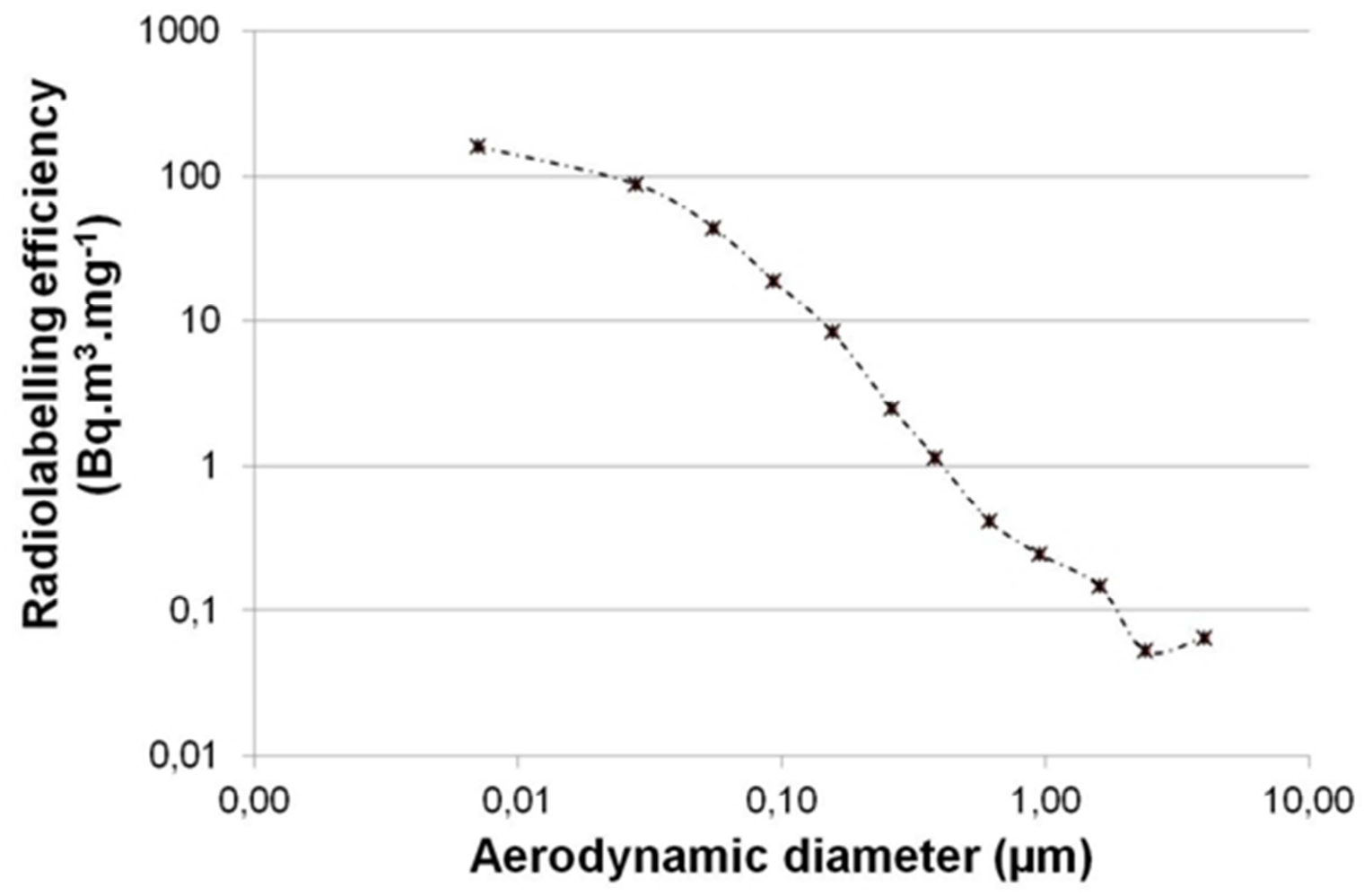


FIGURE 6. Operating parameters influencing Technegas aerodynamic particle size distribution. Clinical operating conditions are used as a reference (distribution in black bold line).

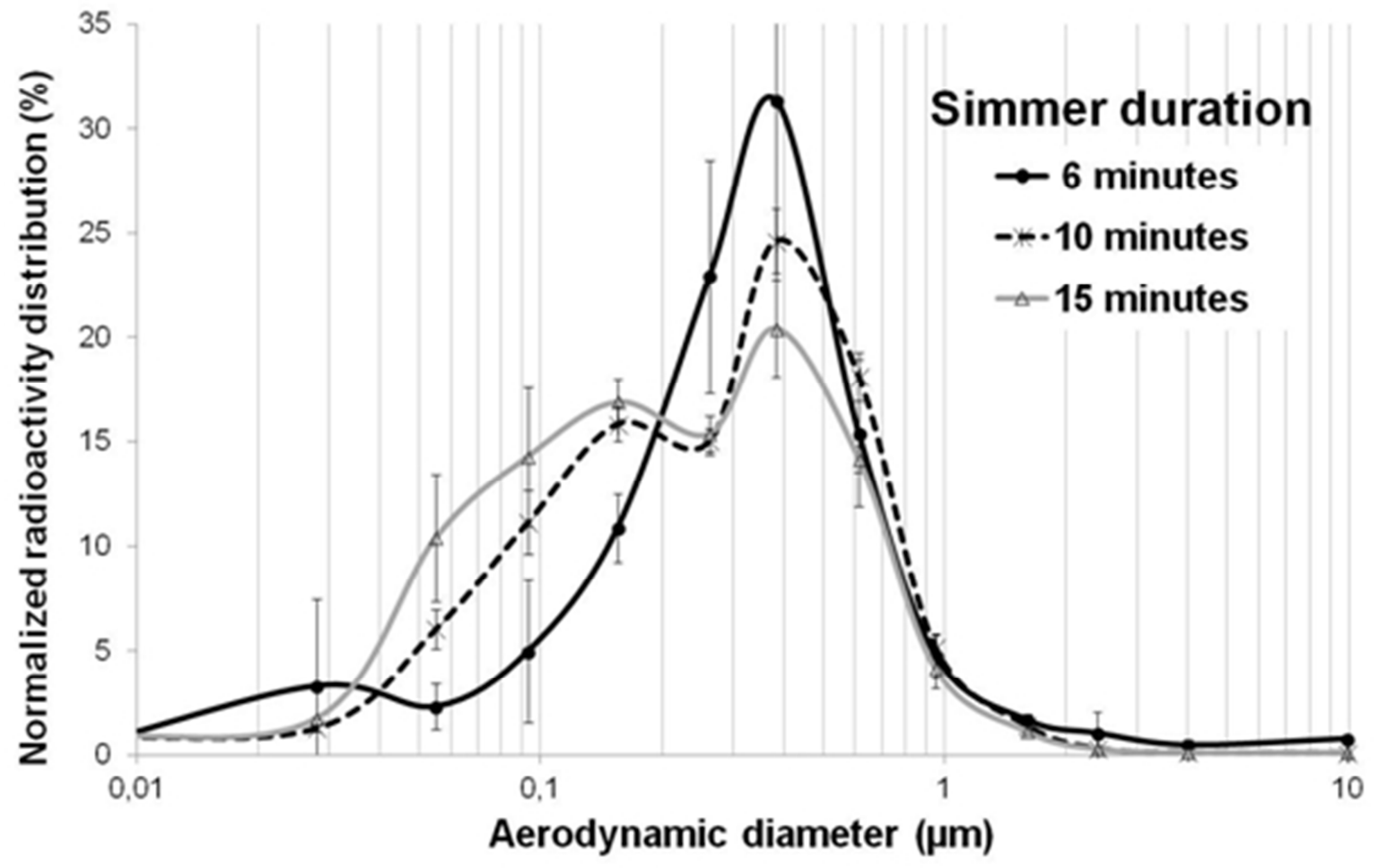

27

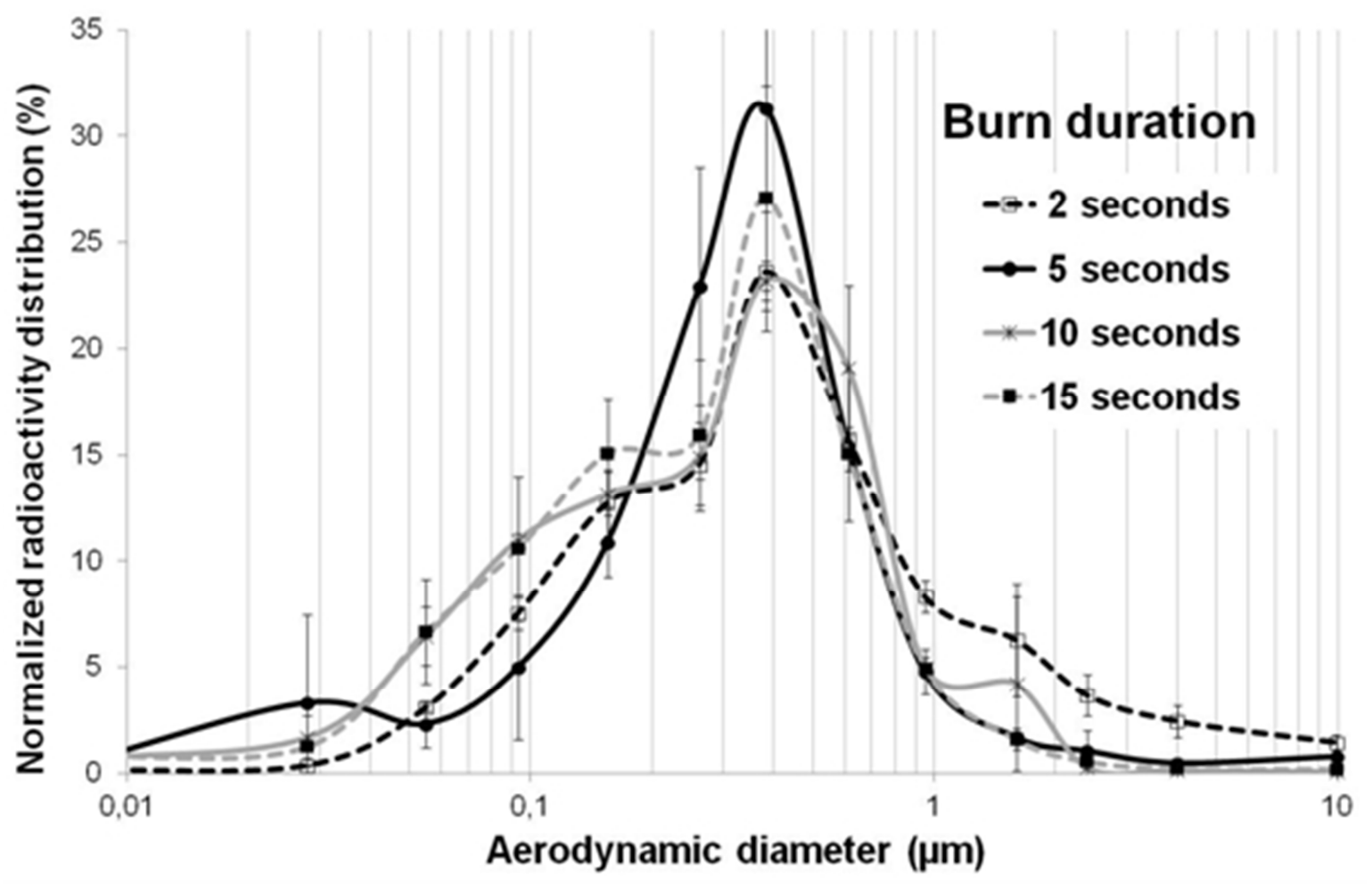



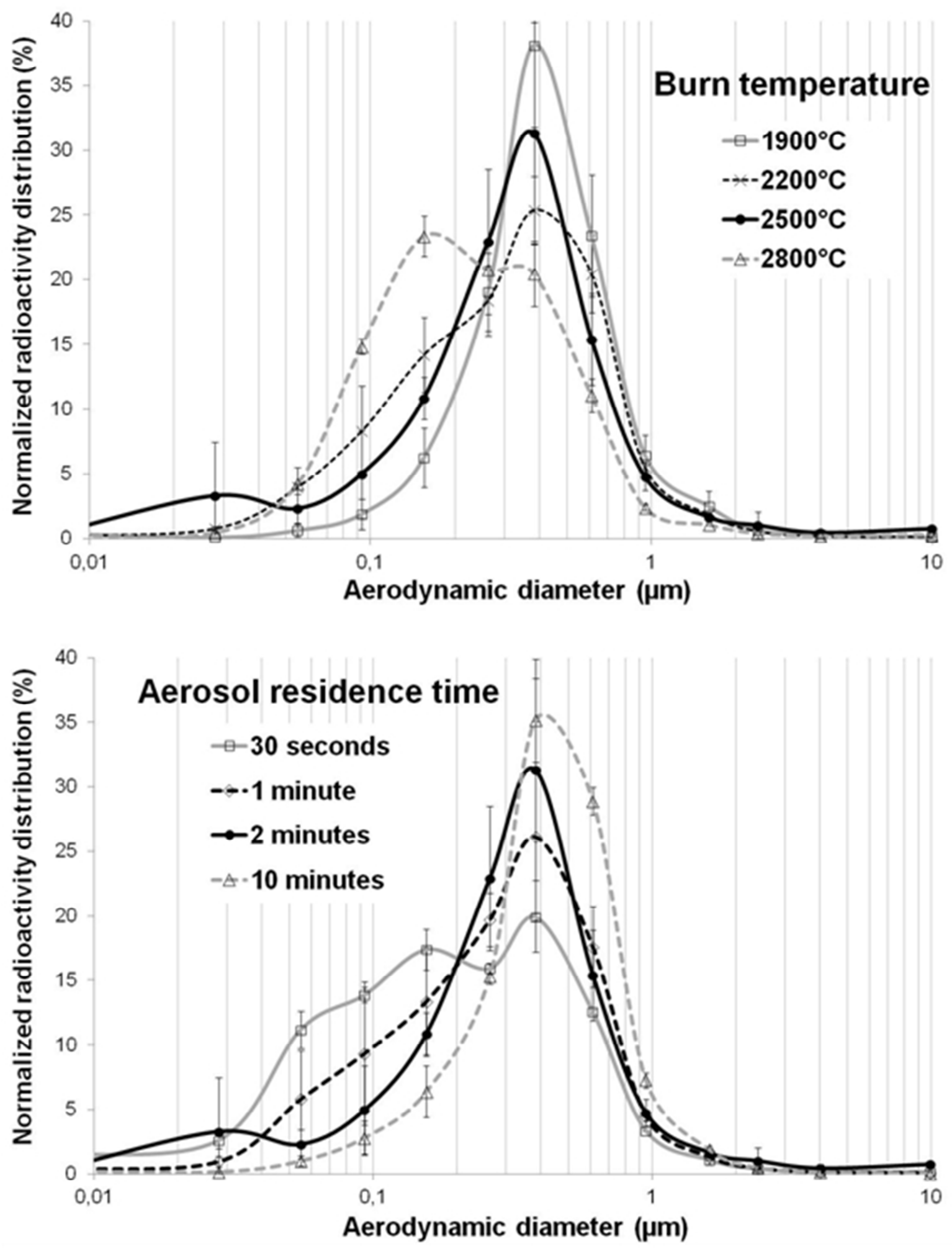
33 FIGURE 7. SEM images of particles deposited on ELPI stage corresponding to mid34 point aerodynamic diameter of $2.39 \mu \mathrm{m}$ for residence times of $(A) 30$ seconds and $(B)$ 3510 minutes. Arrows indicate agglomerated particles.
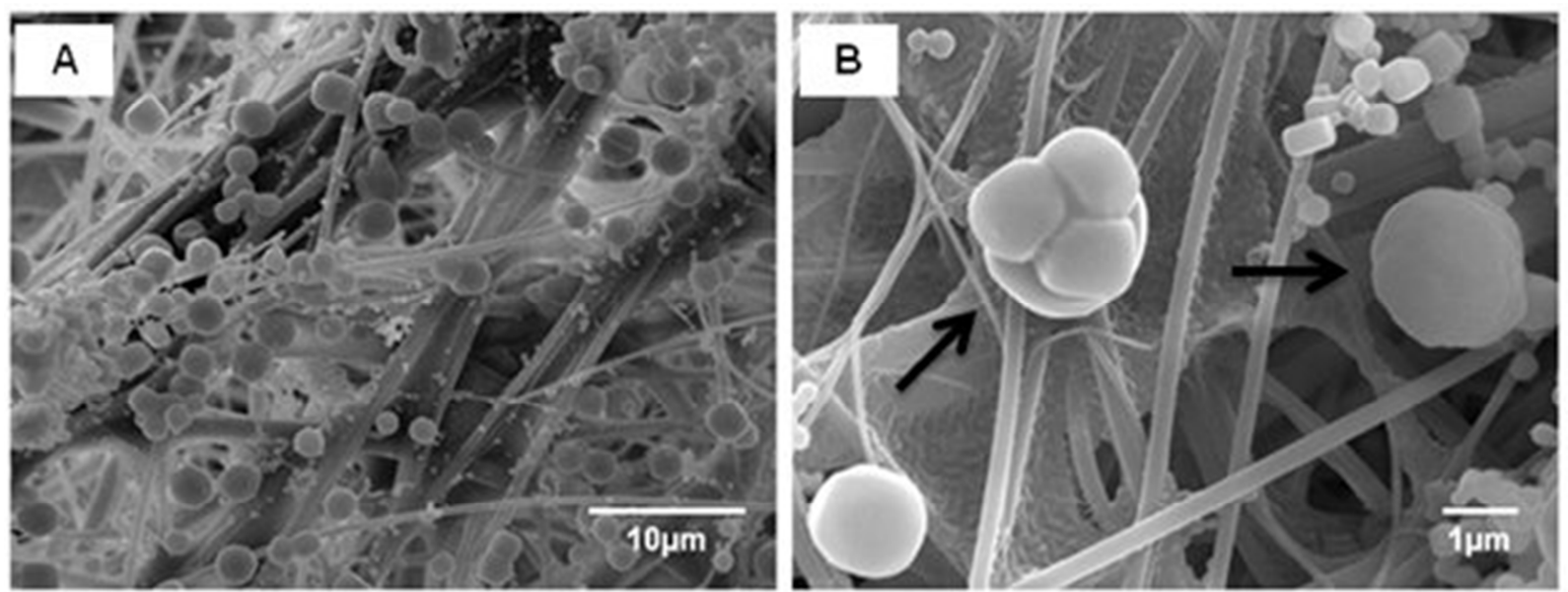
FIGURE 8. Total radioactivity of evaluated radio-aerosols: influence of operating parameters ( ${ }^{*}$ : Values are not significantly different, $\left.p<0.05\right)$.

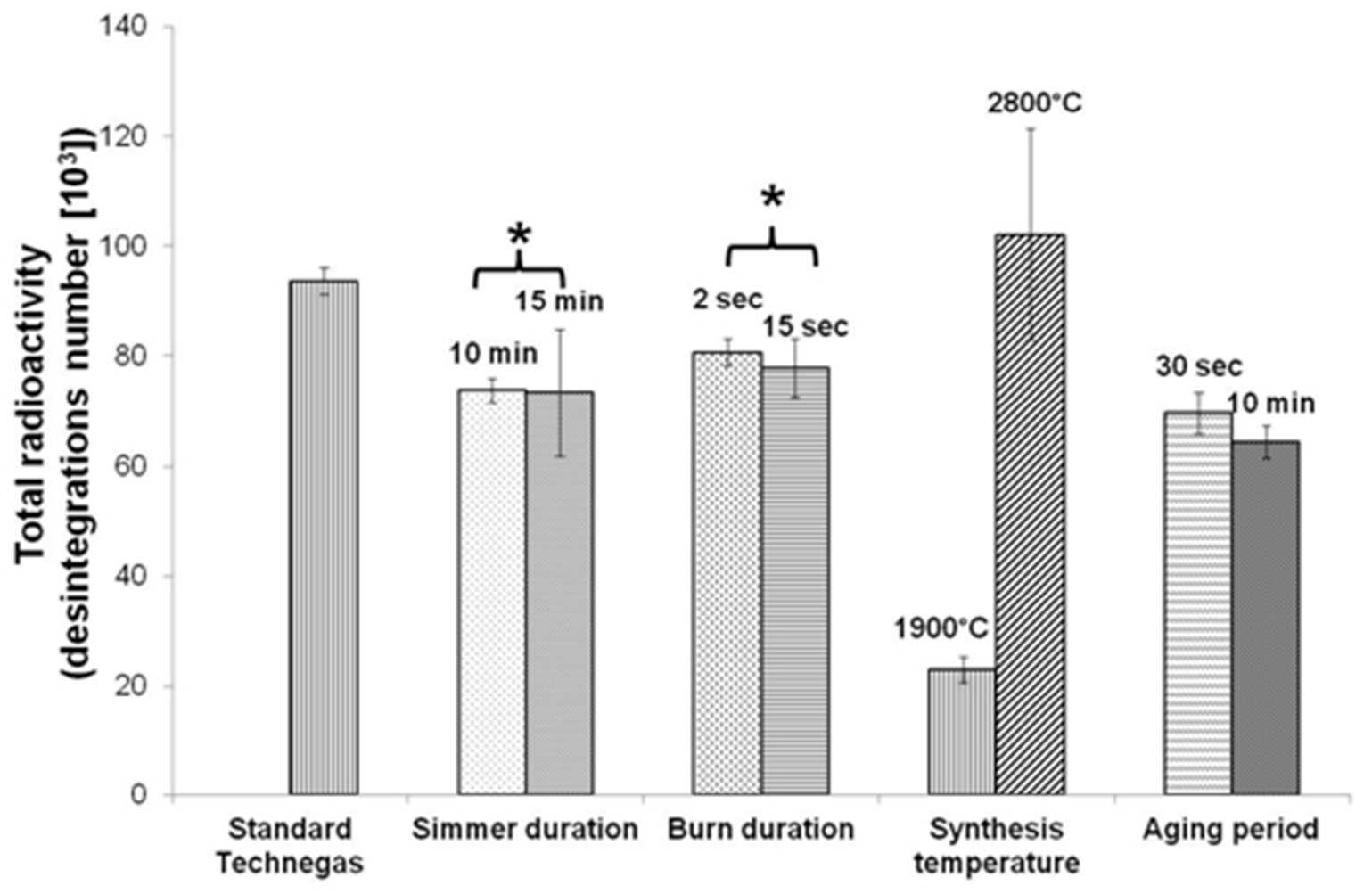


FIGURE 9. Technegas aerodynamic particle size distribution: comparison between

43 standard clinical production, optimized production and optimized production using $\mathrm{NaCl}$ free-eluate.

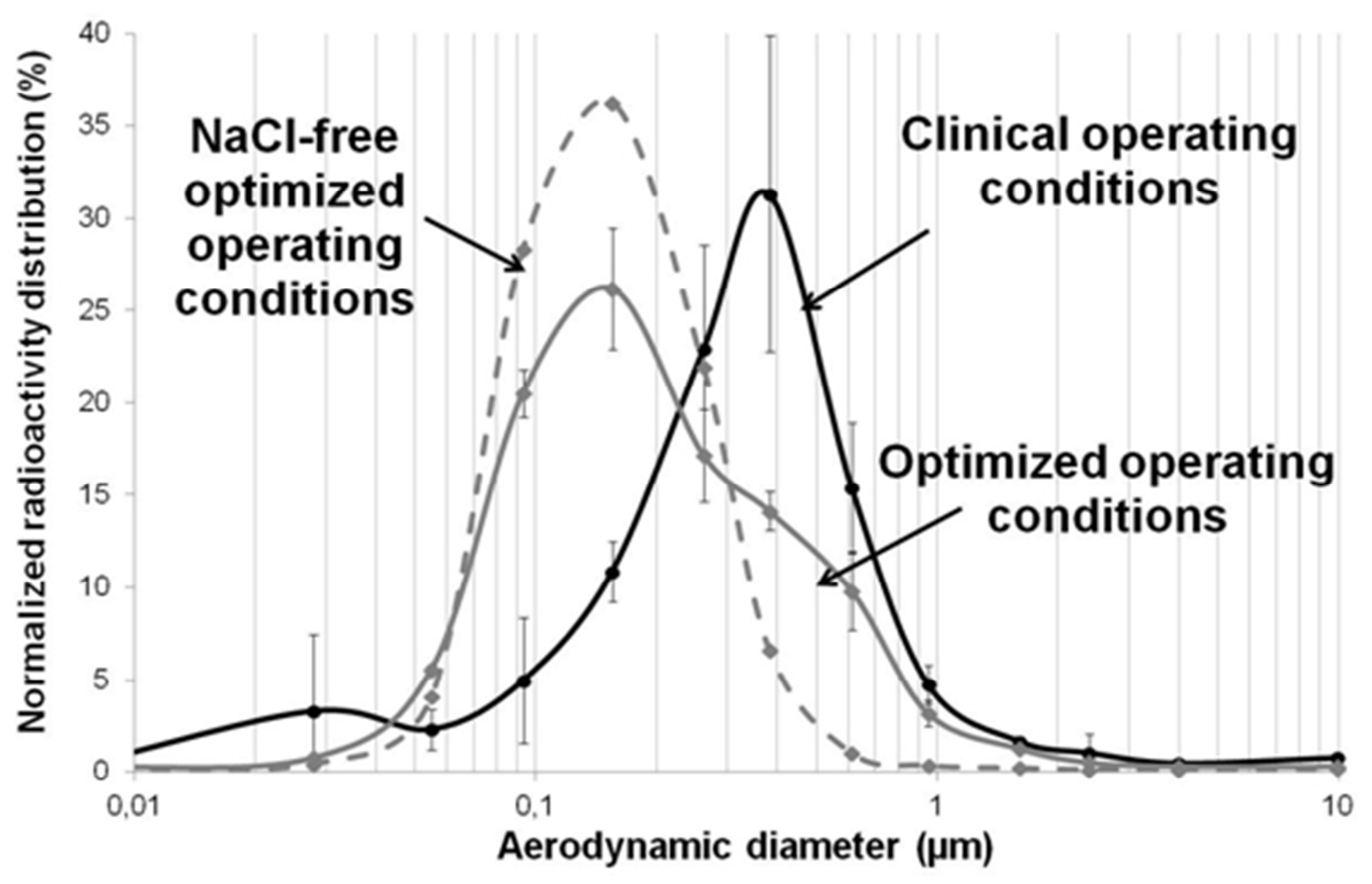


TABLE 1. Influence of ELPI collection substrates on aerosols particle size distributions: radioactivity median aerodynamic diameters (AMAD) and geometric standard deviation (GSD).

\begin{tabular}{cccc}
\hline $\begin{array}{c}\text { Generation } \\
\text { Mode }\end{array}$ & $\begin{array}{c}\text { ELPI } \\
\text { Measurements }\end{array}$ & AMAD (nm) & GSD \\
\hline $\begin{array}{c}\text { without } \\
\text { standard } \\
\text { coperating } \\
\text { conditions }\end{array}$ & $\begin{array}{c}\text { substrates } \\
\text { with collection } \\
\text { substrates }\end{array}$ & $450^{*}$ & 3.4 \\
\hline
\end{tabular}

${ }^{*}$ : values are not significantly different $(p<0.05)$ 
TABLE 2. Radioactivity median aerodynamic diameters (AMAD) and geometric standard deviation (GSD) under standard clinical operating conditions, or under modified and optimized operating conditions (modified generation parameters in bold).

\begin{tabular}{|c|c|c|c|c|c|c|}
\hline \multirow[b]{2}{*}{$\begin{array}{c}\text { Analyzed } \\
\text { parameters }\end{array}$} & \multicolumn{4}{|c|}{ Generation parameters } & \multicolumn{2}{|c|}{ Particle size distribution } \\
\hline & $\begin{array}{c}\text { Simmer } \\
\text { duration } \\
\text { (min) }\end{array}$ & $\begin{array}{l}\text { Burn } \\
\text { duration } \\
\text { (s) }\end{array}$ & $\begin{array}{c}\text { Synthesis } \\
\text { temperature } \\
\left({ }^{\circ} \mathrm{C}\right)\end{array}$ & $\begin{array}{l}\text { Residence } \\
\text { time } \\
\text { (min) }\end{array}$ & AMAD $(n m)$ & GSD \\
\hline Standard & 6 & 5 & 2500 & 2 & 450 & 2.7 \\
\hline \multirow{2}{*}{$\begin{array}{l}\text { Simmer } \\
\text { duration }\end{array}$} & 10 & 5 & 2500 & 2 & $380^{*}$ & 2.1 \\
\hline & 15 & 5 & 2500 & 2 & 305 & 2.2 \\
\hline \multirow{3}{*}{$\begin{array}{c}\text { Burn } \\
\text { duration }\end{array}$} & 6 & 2 & 2500 & 2 & 500 & 3.2 \\
\hline & 6 & 10 & 2500 & 2 & $385^{\star}$ & 2.5 \\
\hline & 6 & 15 & 2500 & 2 & 370 & 2.9 \\
\hline \multirow{3}{*}{$\begin{array}{l}\text { Synthesis } \\
\text { temperature }\end{array}$} & 6 & 5 & 1900 & 2 & 510 & 3.0 \\
\hline & 6 & 5 & 2200 & 2 & 420 & 2.5 \\
\hline & 6 & 5 & 2800 & 2 & 270 & 2.7 \\
\hline \multirow{3}{*}{$\begin{array}{l}\text { Residence } \\
\text { time }\end{array}$} & 6 & 5 & 2500 & 0.5 & 285 & 2.8 \\
\hline & 6 & 5 & 2500 & 1 & $380^{*}$ & 2.5 \\
\hline & 6 & 5 & 2500 & 10 & 540 & 2.6 \\
\hline Optimized & 6 & 10 & $\begin{array}{c}1900^{\circ} \mathrm{C} \\
\text { followed } \\
\text { by } 2800^{\circ} \mathrm{C}\end{array}$ & 2 & 250 & 2.5 \\
\hline
\end{tabular}

${ }^{*}$ : values are not significantly different $(p<0.05)$ 